\title{
The dopamine transporter haplotype and reward-related striatal responses in adult ADHD
}

\author{
Martine Hoogman ${ }^{\mathrm{a}, \mathrm{b}}$, Marten Onnink ${ }^{\mathrm{a}}$, Roshan Cools ${ }^{\mathrm{a}, \mathrm{d}}$, Esther Aarts ${ }^{\mathrm{a}, \mathrm{d}}$, \\ Cornelis Kan ${ }^{\mathrm{a}}$, Alejandro Arias Vasquez ${ }^{\mathrm{a}, \mathrm{b}}$, Jan Buitelaar ${ }^{\mathrm{c}, \mathrm{e}}$, \\ Barbara Franke ${ }^{a, b, *}$
}

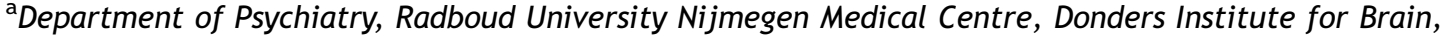 \\ Cognition and Behaviour, Nijmegen, The Netherlands \\ ${ }^{\mathrm{b}}$ Department of Human Genetics, Radboud University Nijmegen Medical Centre, Donders Institute for Brain, \\ Cognition and Behaviour, Nijmegen, The Netherlands \\ 'Department of Cognitive Neuroscience, Radboud University Nijmegen Medical Centre, Donders Institute for Brain, \\ Cognition and Behaviour, Nijmegen, The Netherlands \\ ${ }^{\mathrm{d}}$ Radboud University Nijmegen, Donders Institute for Brain, Cognition and Behaviour, Centre for Cognitive Neuroimaging, \\ Nijmegen, The Netherlands \\ ${ }^{\mathrm{e}}$ Karakter Child and Adolescent Psychiatric University Centre, Nijmegen, The Netherlands
}

Received 16 February 2012; received in revised form 7 May 2012; accepted 29 May 2012
KEYWORDS
ADHD;
Striatum;
DAT1 gene;
Genetic imaging;
Reward;
Dopamine

\begin{abstract}
Attention deficit/hyperactivity disorder (ADHD) is a highly heritable disorder and several genes increasing disease risk have been identified. The dopamine transporter gene, SLC6A3/DAT1, has been studied most extensively in ADHD research. Interestingly, a different haplotype of this gene (formed by genetic variants in the $3^{\prime}$ untranslated region and intron 8 ) is associated with childhood ADHD (haplotype 10-6) and adult ADHD (haplotype 9-6). The expression of DAT1 is highest in striatal regions in the brain. This part of the brain is of interest to ADHD because of its role in reward processing is altered in ADHD patients; ADHD patients display decreased striatal activation during reward processing. To better understand how the DAT1 gene exerts effects on ADHD, we studied the effect of this gene on reward-related brain functioning in the area of its highest expression in the brain, the striatum, using functional magnetic resonance imaging. In doing so, we tried to resolve inconsistencies observed in previous studies of healthy individuals and ADHD-affected children. In a sample of 87 adult ADHD patients and 77 healthy comparison subjects, we confirmed the association of the 9-6 haplotype with adult ADHD. Striatal hypoactivation during the reward anticipation phase of a monetary incentive delay task in $A D H D$ patients was again shown, but no significant effects of DAT1 on striatal activity were found.
\end{abstract}

*Correspondence to: Department of Human Genetics (855), Radboud University Nijmegen Medical Centre, P.O. Box 9101, 6500 HB Nijmegen, The Netherlands. Tel.: + 3124 3610181; fax: + 31243616658.

E-mail address: B.Franke@gen.umcn.nl (B. Franke). 
Although the importance of the DAT1 haplotype as a risk factor for adult ADHD was again demonstrated in this study, the mechanism by which this gene increases disease risk remains largely unknown.

(c) 2012 Elsevier B.V. and ECNP. All rights reserved.

\section{Introduction}

Attention-deficit/hyperactivity disorder (ADHD) is a very common and highly heritable neuropsychiatric disorder in childhood that is strongly persistent over time. Approximately $15 \%$ of patients still meet full ADHD criteria according to DSM-IV criteria in adulthood, and 40-60\% remits only partially and has increased symptom counts and impaired functioning in adulthood (Faraone et al., 2006). ADHD has an average prevalence between 2.5 and $4.9 \%$ in the adult population (Simon et al., 2009).

The clinical phenotype of ADHD is characterized by symptoms of inattention, hyperactivity and impulsivity (Frances, 2000). Neuropsychological theories have described three key domains that are deficient in ADHD. Besides executive dysfunctioning and timing problems, patients with ADHD often display reward and motivational problems (Sonuga-Barke, 2003; Sonuga-Barke et al., 2010). Evidence for these problems can be found on a behavioral level, where ADHD patients show altered performance on reward-related tasks, with steeper discounting rates and an aversion for delay of gratification being the most studied and replicated processes (Luman et al., 2005). In addition, neuroimaging studies have shown ventral striatal hypoactivation in ADHD patients (Scheres et al., 2007; Ströhle et al., 2008; Hoogman et al., 2011) during reward anticipation.

Linkage and association studies have identified several genes associated with ADHD (Franke et al., 2011). One of these genes is the SLC6A3/DAT1 gene, for which the association with ADHD was confirmed in meta-analyses of candidate gene studies in ADHD (e.g., Gizer et al., 2009). The DAT1 gene, encoding the dopamine transporter, contains two frequently studied variable number of tandem repeat (VNTR) polymorphisms. One is a 40 base pair (bp) VNTR in the $3^{\prime}$ untranslated region (UTR); the 9-repeat and 10-repeat alleles are the most frequent alleles, here (VanNess et al., 2005). The second is the VNTR in intron 8, for which the 5 and 6 repeat alleles are most common. The 10-6 haplotype of these VNTRs has been shown to increase risk for ADHD in childhood (Brookes et al., 2006; Asherson et al., 2007). A different haplotype, the 9-6 haplotype, was found associated with ADHD in adults (Franke et al., 2008, 2010). This could be due to the association of the 9-6 haplotype with a more severe and persistent form of ADHD, already present in childhood, but overrepresented in the adult patients. Also, environmental factors known to influence dopamine transporter regulation like smoking, result in age-dependent associations with DAT1.

Dopamine transporters are predominantly found in the striatum and are responsible for synaptic clearance of dopamine there (Volkow et al., 1998). Genetic variation of the DAT1 gene might lead to individual variation in the availability of dopamine transporters and subsequently in dopamine levels. This was evidenced by Single-Photon Emission Computed
Tomography (SPECT) and Positron Emission Tomography (PET) studies showing the 10-repeat allele to be associated with lower availability of striatal dopamine transporters (potentially leading to higher dopamine levels) than the 9-repeat allele (Shumay et al., 2011; van de Giessen et al., 2009). However, some smaller sampled studies propose the opposite (e.g., Heinz et al., 2000), and a meta-analysis of these studies has also stayed inconclusive (Costa et al., 2011). A recent publication by Shumay and coworkers suggests that there is differential decay of dopamine transporter expression with age for different DAT1 genotypes, also including the 9-6 and 10-6 haplotypes (Shumay et al., 2011). The 9-repeat homozygotes showed a steeper decline of DAT availability with increasing age. This could be an alternative or additional explanatory factor for the differential association of DAT1 haplotypes with ADHD in children and adults.

To better understand how variation in the DAT1 gene affects the phenotype, several studies have investigated the association of this gene with brain responses and behavior. Most of these studies were directly aimed at striatal activation and some of its behavioral correlates, reward processing and response inhibition. Three studies in healthy adults found lower reward-related striatal activation to be associated with homozygosity for the 10-repeat of the $3^{\prime}$ UTR VNTR compared to 9-repeat carriership, two other studies did not find an effect of DAT1 genotype (Table 1). In children with ADHD, one study found lower striatal activation to be associated with the homozygous 10-repeat compared to 9-repeat carriership (Durston et al., 2008), whereas another study found the opposite (Bédard et al., 2010). So far, there have not been any functional studies on the effects of the DAT1 gene on striatal functioning in adults with $A D H D$, nor have any studies investigated the role of the DAT1 VNTR haplotype on striatal functioning.

To learn more about the role of DAT1 in adult ADHD, in the current study we tried to replicate the association of the 9-6 haplotype and adult ADHD. To resolve the inconsistencies between previous genetic neuroimaging studies of DAT1, we also studied striatal brain responses, for which ADHD patients and controls performed a reward anticipation task inside a Magnetic Resonance Imaging (MRI) scanner, a task known to robustly induce striatal activation (Knutson et al., 2001; Hoogman et al., 2011). Given the previous studies, we expected (1) an association between the 9-6 haplotype and adult ADHD, and (2) the striatal hypoactivation previously shown in ADHD patients to be explained by variation in the DAT1 gene.

\section{Experimental procedures}

\subsection{Participants}

One hundred and sixty-five individuals ( 87 adult ADHD patients, 77 comparison subjects) from the Dutch cohort of the International 
Table 1 Review of studies investigating the influence of the DAT1 3' UTR VNTR on striatal activation in healthy subjects and patients with ADHD.

\begin{tabular}{|c|c|c|c|c|c|c|c|}
\hline Study & Population & Age & $n$ & fMRI Task & Striatal region analyzed & $\begin{array}{l}9 R \text { vs. } 10 / 10 \text { significant } \\
\text { difference in VS } \\
\text { activation }\end{array}$ & Other findings \\
\hline Dreher et al. (2009) & Healthy & \pm 27 & 22 & $\begin{array}{l}\text { MID (noWin, winLow, } \\
\text { winHigh); anticipation } \\
\text { phase }\end{array}$ & $\begin{array}{l}\text { Functional VS and } \\
\text { caudate }\end{array}$ & $10 / 10<9 R$ & \\
\hline Forbes et al. (2009) & Healthy & $44.2 \pm 6.8$ & 86 & $\begin{array}{l}\text { Reward card guessing } \\
\text { game }\end{array}$ & $\begin{array}{l}\text { VS; Sphere }(20 \mathrm{~mm} \text {, } \\
0,10,-10)\end{array}$ & $10 / 10<9 R$ & \\
\hline Hahn et al. (2010) & Healthy & $18-47$ & 53 & $\begin{array}{l}\text { MID (winLow, winHigh, } \\
\text { loose) }\end{array}$ & $\begin{array}{l}\text { VS; Sphere }(20 \mathrm{~mm} \text {, } \\
0,10,-10)\end{array}$ & no & $\begin{array}{l}10 / 10 \text { had association } \\
\text { with impulsivity, } 9 R \text { did } \\
\text { not }\end{array}$ \\
\hline Aarts et al. (2010) & Healthy & $18-27$ & 20 & $\begin{array}{l}\text { Combined reward/task- } \\
\text { switching; anticipation } \\
\text { phase }\end{array}$ & Left caudate (AAL) & $10 / 10<9 R$ & $\begin{array}{l}\text { In } 9 R \text { a reward effect } \\
\text { was found (high vs. low } \\
\text { reward), } 10 R \text { did not } \\
\text { show a reward effect }\end{array}$ \\
\hline Nikolova et al. (2011) & Healthy & $44.5 \pm 6.7$ & 69 & $\begin{array}{l}\text { Reward card guessing } \\
\text { game }\end{array}$ & $\begin{array}{l}\text { VS; Sphere }\left(2 \times 10 \mathrm{~mm}^{2} \text {, }\right. \\
12,12,-10)\end{array}$ & no & \\
\hline Durston et al. (2008) & $\mathrm{ADHD}$ & $11-20$ & 29 & Go/No-go & caudate & $10 / 10<9 R$ & $\begin{array}{l}10 / 10<9 R \text { for caudate } \\
\text { in ADHD but not in } \\
\text { controls }(n=9)\end{array}$ \\
\hline Bédard et al. (2010) & $\mathrm{ADHD}$ & $7-16$ & 41 & Go/No-go & $\begin{array}{l}\text { Striatum (functional } \\
\text { ROI) }\end{array}$ & $\begin{array}{l}10 / 10>9 R \text { (left striatum } \\
-16,-1,9)\end{array}$ & \\
\hline
\end{tabular}

Abbreviations: noWin=condition without reward; winLow=condition with a small reward; winHigh=condition with high reward; MID=Monetary Incentive Delay task; VS=ventral striatum; $\mathrm{AAL}=$ automated anatomical labeling; $\mathrm{ROI}=$ region of interest. 
Multicentre persistent ADHD CollaboraTion, IMPACT (Sánchez-Mora et al., 2010), participated in this study.

All participants underwent cognitive testing and neuroimaging. The ADHD patients and the age-, gender- and IQ-comparable group of healthy subjects were recruited from the department of Psychiatry of the Radboud University Nijmegen Medical Centre and through advertisements. Patients were included if they met DSM-IV-TR criteria for ADHD in childhood as well as adulthood. All subjects were assessed using the Diagnostic Interview for Adult ADHD (DIVA) (Kooij, 2010). This interview focuses on the 18 DSM-IV symptoms of ADHD and uses concrete and realistic examples to thoroughly investigate whether the symptom is present now or was in childhood. In order to obtain information about ADHD symptoms and impairment in childhood, additional information was obtained from parents and school reports, whenever possible. The Structured Clinical Interview for DSM-IV Criteria (SCID-I) was used for comorbidity assessment. Assessments were carried out by trained professionals (psychiatrist or psychologists). In addition, a quantitative measure of clinical symptoms was obtained using the ADHDDSM-IV Self Rating scale (Kooij et al., 2005).

Exclusion criteria for participants were psychosis, addiction in the last 6 months, current major depression (assessed with SCID-I), full-scale IQ estimate less than 70 (Wechsler Adult Intelligence Scale-III), neurological disorders, sensorimotor handicaps, nonCaucasian ethnicity and medication use other than psychostimulants or atomoxetine. Additional exclusion criteria for comparison subjects were a current or past neurological or psychiatric disorder according to SCID-I. Twenty-seven (31\%) ADHD patients were medication-naive at the time of the trial. Patients who used ADHD medication (methylphenidate $(n=50)$, atomoxetine $(n=3)$ and dextroamphetamine $(n=7)$ ) were asked to withhold their medication $24 \mathrm{~h}$ prior to testing. Subjects had to refrain from smoking prior to and during testing, because smoking results in global reductions of brain activity and increased dopamine concentrations in the striatum (Brody, 2006). The effects of smoking were controlled for by taking smoking habits (yes/no) into account in our analysis.

This study was approved by the regional ethics committee. Written informed consent was obtained from all participants.

\subsection{Genotyping}

DNA was isolated from EDTA blood samples. Genotyping of the 40 base pair VNTR in the $3^{\prime}$ UTR and the VNTR in intron 8 of SLC6A3/ DAT1 were carried out as described before (Franke et al., 2008) at the department of Human Genetics of the Radboud University Nijmegen Medical Centre. Haplotypes were calculated using the Haplostats package (R version 2.12.0) (Schaid et al., 2002). For the behavioral and functional data analysis, risk haplotype (9-6) carriers were compared with non-carriers. To increase comparability with previous studies (see Table 1 ) reporting the effect of the 40 base pair VNTR in the $3^{\prime}$ UTR, we also compared $9 R$ carriers to $10 / 10$ homozygotes.

\section{3. fMRI reward anticipation paradigm}

Subjects were scanned while performing a modified Monetary Incentive Delay task (which has shown to induce striatal activation (Hermans et al., 2010; Knutson et al., 2001)) to study neural responses to reward anticipation (Supplement \#1 in Appendix A). The current sample is an expansion of an earlier published sample (ADHD: 63 versus 87 (72\% overlap), comparison subjects: 41 versus 77 (53\% overlap)), in which this task was applied (Hoogman et al., 2011). Subjects were asked to respond as quickly as possible to a target by pressing a button. Prior to this target a cue (duration 3.5$8.5 \mathrm{~s}$ ) was given to indicate whether a reward could be obtained or not. After each target response the outcome was displayed. Subjects could gain 1 Euro in the reward condition and no money during the no-reward condition if they responded between 270 and $500 \mathrm{~ms}$ after target-onset. This response window was individually adjusted (Supplement \#1 in Appendix A). The task consisted of a practice trial, after which the purpose of the task was again briefly summarized, followed by 50 trials in which reward and no-reward cues were randomly displayed. The experiment lasted $12 \mathrm{~min}$ and 12 Euros could be gained. At the end of the experiment, the awarded money was shown on the screen and was transferred to the participant's bank account. Reaction times in the reward and noreward condition were the behavioral outcome measures. In addition to this task, participants performed other cognitive tasks inside and outside the MRI scanner.

\subsection{Statistical analysis}

\subsubsection{Haplotype association with ADHD}

To replicate the association of the 9-6 haplotype with ADHD, a chisquare test was performed comparing the presence of the 9-6 haplotype in ADHD patients with presence in controls. Part of the patient sample included in this analysis was also part of earlier publications investigating this association (overlap of ADHD patients between studies: $n=17$, no overlap in controls) (Franke et al., 2008; Franke et al., 2010). In addition, we studied the role of the 9-6 haplotype in patients with respect to ADHD severity by performing a $t$-test with the number of Hyperactive/Impulsive symptoms and the number of Inattentive symptoms as dependent variable and presence of the 9-6 haplotype as grouping variable.

\subsubsection{Behavioral analysis}

A repeated measures general linear model was performed to assess the effect of cue (reward/no-reward) on response time. This general linear model was carried out with reaction times as dependent variable and reward/no-reward cue as within subject variable. To test the effect of the between-subject factors, ADHD status and DAT1 haplotype (carrier/non-carrier) or $3^{\prime}$ UTR VNTR genotype ( $9 \mathrm{R}$ carrier/10R homozygous) were added to the model to identify group effects of cue-induced reaction times.

\subsection{3. fMRI analysis}

After preprocessing (for details on fMRI acquisition and preprocessing, see Supplement \#2 in Appendix A), first-level analyses were performed for each subject to estimate 8 parameters of interest with a general linear model for the events 'cue', 'target', 'hit', 'miss' in both the reward and the no-reward condition. These events were modeled as event-related regressors, with duration 0 and convolved with the canonical hemodynamic response function in SPM5 (Wellcome Dept. of Cognitive Neurology, London). Additionally, realignment parameters were included to account for movement-related variability, and timederivatives were used, which resulted in 14 additional regressors of no interest. Data were high-pass filtered using a cut-off of $1 / 128 \mathrm{~Hz}$.

To assess neural activation associated with reward anticipation, the reward and no-reward cues were contrasted ('reward cue' $>$ 'no-reward cue'). The contrast images for these events were submitted to a second-level random effect analysis with a full factorial $2 \times 2 \times 2$ design: ADHD status (patient/healthy control), DAT1 haplotype or genotype and cue (reward vs. no-reward). Age and gender were included as covariates (Becker, 1999; Mell et al., 2009). For the whole brain analysis the main effect of cue was tested using a threshold of $p<0.05$, family-wise error corrected, and a cluster size threshold of 50 voxels. Because of our a priori hypothesis regarding the striatum, our region of interest was determined by taking the supra-threshold striatal activation in the whole brain analysis of our contrast of interest ('reward cue' > 'no-reward cue') main effect of cue. The beta weights of this region of interest were extracted using Marsbar (Brett et al., 2002) and used in the analysis to investigate group effects (ADHD status and DAT1 haplotype). 
To replicate previous studies (Scheres et al., 2007; Ströhle et al, 2008; Hoogman et al., 2011), which observed striatal hypoactivation in ADHD patients without taking the effect of DAT1 into account, a $t$ test was performed with ADHD status as independent variable and averaged task-related striatal activation as dependent variable. The effect of the DAT1 haplotype was subsequently determined by performing an ANOVA on task-related averaged striatal activation, including $A D H D$ status and DAT1 haplotype as independent variables. In addition, the effect of the DAT1 3' UTR VNTR genotype was tested in a similar way as the effect of the haplotype. All statistical tests were two-sided, unless stated otherwise.

\section{Results}

Demographics of the sample of 87 adult ADHD patients and 77 comparison subjects are displayed in Table 2, genotype and haplotype distribution is shown in Table 3. Patients and controls did not differ on age, percentage men or estimated IQ $(p>0.22)$. DAT1 risk haplotype (9-6) carriers did not differ from non-carriers on any of the demographic variables, neither did groups differ on such variables based on single VNTR genotypes (DAT1 3' UTR and DAT1 intron 8; data not shown). Patients had higher ADHD scores compared with healthy controls (A: $p<0.001$, HI: $p<0.001$; see Table 2 ).

\subsection{ADHD and the DAT1 haplotype}

A higher prevalence of the risk haplotype was found in adults with $\mathrm{ADHD}$ compared with healthy controls, $\left[\chi^{2}=\right.$ $10.04, p=0.002$, Table 3]. Also, patients carrying the DAT1 risk haplotype had more inattentive symptoms $[t(85)=2.68$, $p=0.009]$, but not hyperactive/impulsive symptoms $[t(85)=0.61, p=0.54]$ than patients not carrying this haplotype. Within the healthy comparison group no symptom count differences based on haplotype carriership were found.

Comparisons based on single VNTR genotypes showed higher inattentive symptom levels in ADHD patients carrying the DAT1 3' UTR VNTR 9-repeat allele compared with ADHD patients homozygous for the 10 -repeat allele $[t(83)=2.79$, $p=0.007]$, but no differences in hyperactive/impulsive symptoms $[t(83)=0.09, p=0.93]$. There were no differences in ADHD symptom counts between patient groups based on DAT1 intron 8 genotype or in any comparisons of single VNTR genotypes within the healthy comparison group.

Table 3 DAT1 VNTR 3'UTR and intron 8 haplotypes and genotypes.

\begin{tabular}{lcc}
\hline Haplotype & ADHD $(n=87)$ & Controls $(n=77)$ \\
\hline $5-9$ & 29 & 26 \\
$5-10$ & 2 & 11 \\
$6-9^{a}$ & 25 & 7 \\
$6-10$ & 112 & 110 \\
$6-11$ & 3 & 0 \\
$13-10$ & 1 & 0 \\
$14-10$ & 1 & 0 \\
14-11 & 1 & 0 \\
\hline Genotype & ADHD $\left(n=88^{\text {b }}\right)$ & Controls $(n=77)$ \\
\hline DAT1 3'UTR 9/9 & 7 & 4 \\
DAT1 3'UTR 9/10 & 38 & 25 \\
DAT1 3'UTR 10/10 & 38 & 48 \\
DAT1 3'UTR 9/11 & 2 & 0 \\
DAT1 3'UTR 10-11 & 2 & 0 \\
DAT1 intron8 5/5 & 2 & 3 \\
DAT1 intron8 5/6 & 26 & 31 \\
DAT1 intron8 6/6 & 56 & 43 \\
DAT1 intron8 6/13 & 1 & 0 \\
DAT1 intron8 5/14 & 1 & 0 \\
DAT1 intron8 6/14 & 1 & 0 \\
\hline
\end{tabular}

a9-6 was indicated to be the risk haplotype and showed an association with ADHD.

'The subject with 10-11 DAT1 3'UTR was not included in the analysis.

Table 2 Demographics of the study sample.

\begin{tabular}{|c|c|c|c|c|c|c|c|c|}
\hline & \multicolumn{4}{|c|}{ ADHD } & \multicolumn{4}{|c|}{ Healthy controls } \\
\hline & \multicolumn{2}{|c|}{$\begin{array}{l}\text { Risk haplotype } \\
(n=25)\end{array}$} & \multicolumn{2}{|c|}{$\begin{array}{l}\text { No risk haplotype } \\
(n=62)\end{array}$} & \multicolumn{2}{|c|}{$\begin{array}{l}\text { Risk haplotype } \\
(n=7)\end{array}$} & \multicolumn{2}{|c|}{$\begin{array}{l}\text { No risk haplotype } \\
(n=70)\end{array}$} \\
\hline & $M$ & SD & M & SD & $M$ & SD & M & SD \\
\hline Age & 37.3 & 12.8 & 35.2 & 10.1 & 41.43 & 12.5 & 37.0 & 11.0 \\
\hline $1 Q^{b}$ & 11.6 & 2.6 & 11.2 & 2.3 & 12.6 & 2.5 & 11.7 & 2.4 \\
\hline Inattentive symptoms & 7.3 & 1.6 & 6.0 & 2.1 & 0.3 & 0.8 & 0.7 & 1.1 \\
\hline \multirow[t]{2}{*}{ Hyperactive/Impulsive symptoms } & 5.8 & 2.3 & 5.5 & 2.2 & 0.7 & 1.1 & 0.8 & 1.2 \\
\hline & $N$ & $\%$ & $N$ & $\%$ & $N$ & $\%$ & $N$ & $\%$ \\
\hline Male subjects & 6 & 24 & 30 & 48 & 3 & 43 & 28 & 40 \\
\hline Medication naïve subjects & 7 & 28 & 19 & 31 & - & - & - & - \\
\hline
\end{tabular}

${ }^{\text {a }}$ Risk haplotype is the 9-6 haplotype of the 3'UTR VNTR and intron8 VNTR of DAT1.

${ }^{\mathrm{b}}$ Average of standard scores for Block Design and Vocabulary of WAIS-III-R; M=mean, SD=standard deviation. 


\subsection{Modified monetary incentive delay task}

Subjects reacted faster in reward trials (mean $=250 \mathrm{~ms}$ ) than no-reward trials (mean $=289 \mathrm{~ms}),[F(1,161)=296.67$, $p<0.0001]$. ADHD diagnosis $(p=0.54)$, DAT1 haplotype/ genotype $(p=0.16 / 0.67)$ or the interaction of ADHD status and DAT1 haplotype/genotype $(p=0.80 / 0.82)$ did not affect cue-induced reaction time.

Task-related brain activation in the extended sample is similar as before (Hoogman et al., 2011), and is displayed in Supplement \#3 in Appendix A. In the whole brain analysis bilateral striatum, bilateral insula, right pre-supplementary motor area, left middle frontal gyrus and right superior frontal gyrus were more active during the anticipation of 'reward cues' relative to 'no-reward cues' (more details in Supplement \#4 in Appendix A). Further analysis focused on the bilateral striatal activation. Like in previous studies by others (Scheres et al., 2007; Ströhle et al., 2008) and in our smaller sample (Hoogman et al., 2011), the analysis without taking DAT1 haplotype or genotype into account showed ADHD patients to have lower task-related striatal activation compared to healthy subjects $[t(162)=-2.32, p=0.02$; Supplement \#3 in Appendix A].

\subsection{Effect of DAT1 on striatal activation}

Including both ADHD status and DAT1 haplotype in the whole brain effect of reward cue $>$ no-reward cue, no effect of DAT1 haplotype was observed. Neither was there an effect of DAT1 haplotype in our region of interest, the bilateral striatum $[F(3,160)=1.40, p=0.24$; Figure 1]. There were also no significant interactions of DAT1 haplotype with ADHD status $[F(3,160)=0.41, p=0.52]$, nor was there an effect on bilateral striatal activation when only the DAT1 3' UTR VNTR genotype was considered $[F(3,158)=0.24, p=0.63]$. An analysis only including patients who were medication-naive at the time of testing $(n=26)$ did not result in significant effects of DAT1 haplotype $(p=0.35)$ or genotype $(p=0.28)$ on striatal activation either. The same accounts for an analysis only including participants with no prior smoking habits (DAT1 haplotype $[F(3,115)=0.71, p=0.40]$; DAT1 genotype $[F(3,115)=1.19, p=0.28])$.

\section{Discussion}

In the current study, the role of the dopamine transporter DAT1 gene in adult ADHD was investigated. First, the association between adult ADHD and the DAT1 VNTR haplotype was studied. Second, the functional effect of the DAT1 gene on reward-related striatal activation was investigated in ADHD patients and healthy controls.

Previous studies have shown, that in contrast to childhood, where the 10-6 haplotype of DAT1 is associated with ADHD, the 9-6 haplotype is associated with ADHD in adults (Franke et al., 2011). In the current study we confirmed this association. In that, we have to mention that a part of the sample investigated here was also part of earlier publications of this association (overlap of ADHD patients between studies: $n=17$, no overlap in controls) (Franke et al., 2008, 2010). We report here, for the first time, that this risk haplotype is also associated with more inattentive symptoms in the ADHD group. This fits well with previous findings in childhood ADHD, where an association between the DAT1 gene and attention problems was found in several studies (Bellgrove et al., 2005, 2009; Loo et al., 2003).

When studying the functional effect of the DAT1 VNTR haplotype and effects of the individual DAT1 genotypes on brain activation during a reward anticipation task, we found no effect on striatal functioning, neither in patients nor in controls. At best, there was a trend for striatum activity to be higher in carriers of the 9-6 risk haplotype in both groups (Figure 1). As shown in Table 1, several earlier studies had described such effects for the DAT1 3' UTR VNTR polymorphism. In healthy individuals, our study equalizes the number of

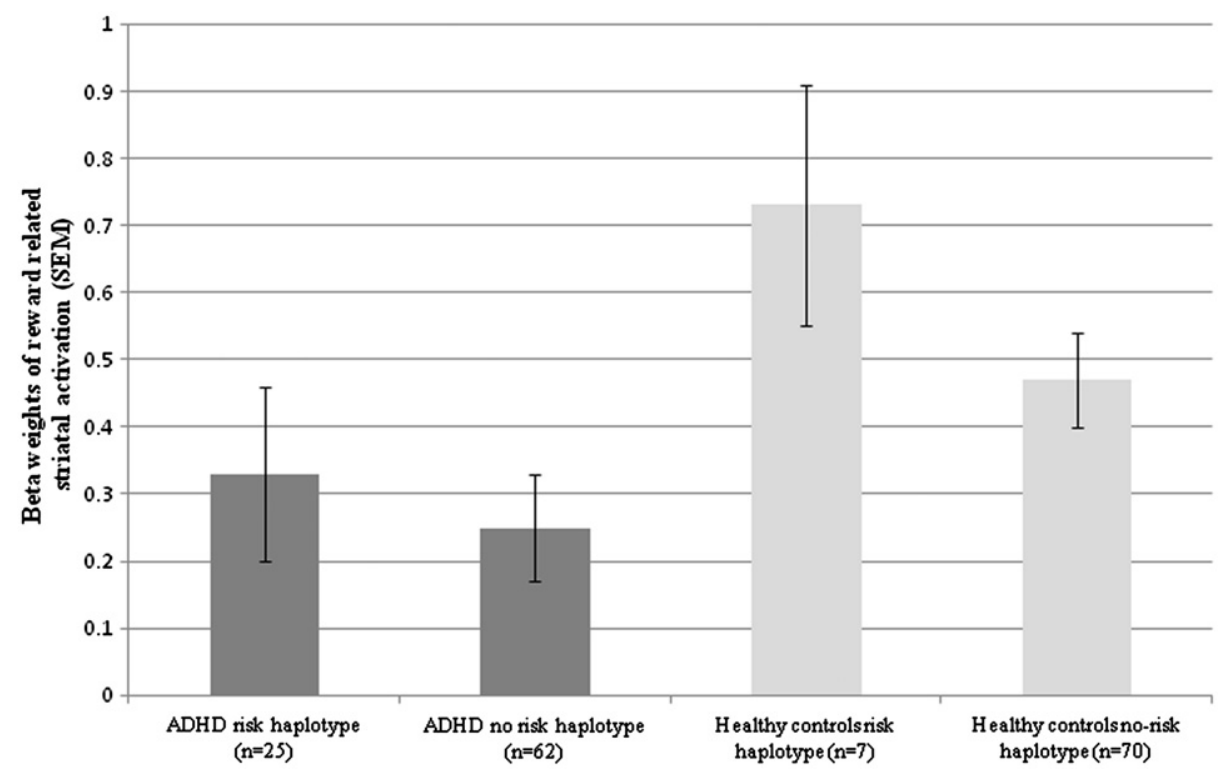

Fig. 1 No effect of the DAT1 risk haplotype on reward-related striatal activation in patients and healthy controls. 
studies observing an effect (more activity in 9-repeat carriers, $n=3)$ to those that did not $(n=2+1)$. The former studies in patients were much smaller, investigated children and were contradicting each other in the direction of effects of the DAT1 gene. It is expected that there are unknown factors that determine the effects of DAT1. One of these factors could be the specifics of the tasks used in the various studies. In the current study, the effect of the DAT1 gene was studied in the reward anticipation phase of a monetary incentive task (Knutson et al., 2001), investigating the effects of motivation (reward $>$ no reward) on a simple reaction time task. The study by Aarts et al. (2010) found an effect of DAT1 3' UTR VNTR genotype on reward anticipation when comparing high versus low reward (i.e., reward magnitude) in the context of a cognitively more demanding task (task-switching). The study by Dreher and co-workers (Dreher et al., 2009), who also reported a significant effect of DAT1, also used a variation in reward magnitude ( 3 levels) and a probability factor during the anticipation phase. Forbes (Forbes et al., 2009) used an alternative card guessing game involving a cognitive component; guessing whether the next card was going to be higher or lower then a given value. This was followed, in correct trials by a reward. The differences in task demands might thus have caused the discrepancies between current and previous studies investigating DAT1 genotype effects on reward anticipation. Indeed, it has been suggested that the effects of striatal dopamine-dependent motivation are highly dependent on cognitive task demands (Aarts et al., 2011, 2010). The missing cognitive component in our task might thus explain the absence of an effect of DAT1 on striatal activation.

Next to specificity of the task, heterogeneity of the study sample might also have an effect on the results. One of the sources of heterogeneity is comorbidity; ADHD is a highly heterogeneous disorder and co-morbid disorders are more often present than not in ADHD (Wilens et al., 2009). There is some evidence that the presence of one of these comorbid disorders, conduct disorder, has an effect on the association between DAT1 and ADHD in children (Zhou et al., 2008): only in ADHD patients without co-morbid conduct disorder an association with DAT1 was observed, although this concerned 5 single nucleotide polymorphisms of the DAT1 gene rather than the VNTRs tested in the current study. In addition, in adult ADHD patients, the presence of comorbid conduct disorder in childhood influences activity in various regions in the brain including the left caudate part of the striatum (Cubillo et al., 2011). Therefore, cognitive functions in ADHD patients with or without a specific comorbid disorder might be differently organized and thus effects of genes may have different effects. In future studies this should be taken into account. Although we did not have information on conduct disorder in our patients available, we took another source of heterogeneity into account, i.e. enviormental factors known to affect dopamine transporter regulation in the striatum (Krause, 2008). However, controlling for smoking and long-term use of stimulant medication by excluding smokers and including only medication-naive subjects in the analysis did not result in the identification of significant effects of DAT1 on striatal functioning.

In the current study we try to explain how genetic variation in DAT1 influences brain responses and consequently behavior.
To understand this process, the intermediate neuromolecular step is also of importance: how are dopamine transporter (DAT) levels affected by genetic variation and by the environment, and do baseline DAT levels differ between patients and controls? Beyond effects of smoking and use of stimulants, regulation of DAT levels is far from clear (Costa et al., 2011; Dougherty et al., 1999; Spencer et al., 2005; Dresel et al., 2000; la Fougère et al., 2006; Krause et al., 2000; Larisch et al., 2006; Hesse et al., 2009; Jucaite et al., 2005; Volkow et al., 2007). Nevertheless, we know that DAT1 is extremely variable in its genetic sequence and also highly sensitive to epigenetic regulation (Shumay et al., 2010; Nieratschker et al., 2012). Understanding such effects would strongly improve the analysis of DAT effects on behavior. PET studies like the recent one by Shumay and coworkers, identifying differential decay of DAT1 expression for different genotypes (Shumay et al., 2011) might bring us a step closer to getting a clearer picture DAT1 function.

Our study sample is the largest adult ADHD imaging genetics study to date and considered large enough to detect effects of single genetic variants (Munafò et al., 2008; Mier et al., 2010; Hoogman et al., 2011). However, not all genetic effects are equally large, as exemplified by the study of Nikolova et al. (2011, Table 1), who investigated the effect of five polymorphisms of genes linked with dopaminergic functioning, including DAT1. While the variation in these genes together explained nearly $11 \%$ of the variance in striatal activation, none of the genes by itself showed a significant association with striatal activation. These results would suggest that we might benefit from performing genewide or neurobiological pathway-wide analyses in the future to understand the polygenic effect on a neurobiological process (Bralten et al., 2011; Ruano et al., 2010).

In conclusion, the importance of the DAT1 haplotype as a risk factor for adult ADHD was again illustrated in this study. However, the mechanism by which DAT1 increases disease risk remains largely unknown. An early review of the effects of the DAT1 3' UTR VNTR on neuropsychological functioning did not show convincing effects of this variant on any particular neuropsychological task (Rommelse et al., 2008). Although it is too early to give up on DAT1 effects on striatal activity for the reasons outlined above, other mechanisms should thus also be considered. To date, there are two studies investigating the effects of DAT1 on brain responses other than those of the striatum, both in adults with ADHD. One of them suggests that brain responses related to cognitive interference result in hypoactivation in the dorsal anterior cingulated cortex (ACC) in patients homozygous for the 10-repeat allele (Brown et al., 2010). A second study showed marginal suppressed effects of DAT1 in the left medial prefrontal cortex during a working memory task, and an interaction effect of diagnosis and genotype on dorsal ACC activity (Brown et al., 2011). Studying DAT1 and the ACC may thus provide additional insights on how DAT1 is related to ADHD. Importantly, the proposed mechanism of DAT1 may be one of modulating the ADHD phenotype instead of having a direct role in causing $A D H D$, as has been suggested several times (Kebir and Joober, 2011; Franke et al., 2008). In this case more attention should be given to studying the role of DAT1 in interaction with other genes. Finally, effects of genes are expected to be subtle, and therefore specific knowledge on neural correlates, external factors (like study design) and 
internal factors (like age) potentially influencing their effects are important to consider in neuroimaging genetics studies, and a sufficiently large sample size is of the essence.

\section{Role of funding source}

Funding for this study was party provided by the Netherlands Brain Foundation (Hersenstichting Nederland), Grant number 15F07(2)27. R. Cools is supported by a VIDI Grant from the Innovational Research Incentives Scheme of the Netherlands Organization for Scientific Research (NWO). Both funders had no further role in study design, in the collection, analysis and interpretation of data, in writing the report, and in the decision to submit the paper for publication.

\section{Contributors}

Hoogman, Onnink, Cools, Kan, Buitelaar and Franke participated in the design of the study. Hoogman, Cools, Aarts, Arias-Vasquez, Buitelaar and Franke wrote the manuscript. Hoogman, Onnink and Kan collected the data. Hoogman and Aarts performed statistical analysis. All authors contributed to and have approved the final manuscript.

\section{Conflict of interests}

In the past 3 years, Jan K. Buitelaar has been a consultant to/member of advisory board of and/or speaker for Janssen Cilag BV, Eli Lilly, Bristol-Myer Squibb, Organon/Shering Plough, UCB, Shire, Medice and Servier. He is not an employee of any of these companies. He is not a stock shareholder of any of these companies. He has no other financial or material support, including expert testimony, patents or royalties. The other authors declare no conflict of interest.

\section{Acknowledgments}

We thank Angelien Heister, Marlies Naber and Remco Makkinje for help with genotyping and Paul Gaalman for technical MRI assistance. We are grateful to all participants for their contribution.

\section{Appendix A. Supporting information}

Supplementary data associated with this article can be found in the online version at http://dx.doi.org/10.1016/ j.euroneuro.2012.05.011.

\section{References}

Aarts, E., Roelofs, A., Franke, B., Rijpkema, M., Fernández, G., Helmich, R.C., Cools, R., 2010. Striatal dopamine mediates the interface between motivational and cognitive control in humans: evidence from genetic imaging. Neuropsychopharmacology 35, 1943-1951.

Aarts, E., van Holstein, M., Cools, R., 2011. Striatal dopamine and the interface between motivation and cognition. Front. Psychol. 2, 163.
Asherson, P., Brookes, K., Franke, B., Chen, W., Gill, M., Ebstein, R.P., Buitelaar, J., Banaschewski, T., Sonuga-Barke, E., Eisenberg, J., Manor, I., Miranda, A., Oades, R.D., Roeyers, H., Rothenberger, A., Sergeant, J., Steinhausen, H.C., Faraone, S.V., 2007. Confirmation that a specific haplotype of the dopamine transporter gene is associated with combined-type ADHD. Am. J. Psychiatry 164, 674-677.

Becker, J., 1999. Gender differences in dopaminergic function in striatum and nucleus accumbens. Pharmacol. Biochem. Behav. 64, 803-812.

Bellgrove, M.A., Hawi, Z., Kirley, A., Gill, M., Robertson, I.H., 2005. Dissecting the attention deficit hyperactivity disorder (ADHD) phenotype: sustained attention, response variability and spatial attentional asymmetries in relation to dopamine transporter (DAT1) genotype. Neuropsychologia 43, 1847-1857.

Bellgrove, M.A., Johnson, K.A., Barry, E., Mulligan, A., Hawi, Z., Gill, M., Robertson, I., Chambers, C.D., 2009. Dopaminergic haplotype as a predictor of spatial inattention in children with attention-deficit/hyperactivity disorder. Arch. Gen. Psychiatry 66, 1135-1142.

Bralten, J., Arias-Vásquez, A., Makkinje, R., Veltman, J.A., Brunner, H.G., Fernández, G., Rijpkema, M. \& Franke, B. (2011) Association of the Alzheimer's gene SORL1 with hippocampal volume in young, healthy adults. Am. J. Psychiatry.

Brett, M., Anton, J., Valabregue, R., Poline, J., 2002. Region of interest analysis using an SPM Toolbox. In: Proceedings of the 8th International Conference on Functional Mapping of the Human Brain, Sendai.

Brody, A., 2006. Functional brain imaging of tobacco use and dependence. J. Psychiatr. Res. 40, 404-418.

Brookes, K., Xu, X., Chen, W., Zhou, K., Neale, B., Lowe, N., Anney, R., Aneey, R., Franke, B., Gill, M., Ebstein, R., Buitelaar, J., Sham, P., Campbell, D., Knight, J., Andreou, P., Altink, M., Arnold, R., Boer, F., Buschgens, C., Butler, L., Christiansen, H., Feldman, L., Fleischman, K., Fliers, E., Howe-Forbes, R., Goldfarb, A., Heise, A., Gabrië]ls, I., Korn-Lubetzki, I., Johansson, L., Marco, R., Medad, S., Minderaa, R., Mulas, F., Müller, U., Mulligan, A., Rabin, K., Rommelse, N., Sethna, V., Sorohan, J., Uebel, H., Psychogiou, L., Weeks, A., Barrett, R., Craig, I., Banaschewski, T., Sonuga-Barke, E., Eisenberg, J., Kuntsi, J., Manor, I., McGuffin, P., Miranda, A., Oades, R.D., Plomin, R., Roeyers, H., Rothenberger, A., Sergeant, J., Steinhausen, H.C., Taylor, E., Thompson, M., Faraone, S.V., Asherson, P., 2006. The analysis of 51 genes in DSM-IV combined type attention deficit hyperactivity disorder: association signals in DRD4, DAT1 and 16 other genes. Mol. Psychiatry 11, 934-953.

Brown, A.B., Biederman, J., Valera, E., Makris, N., Doyle, A., Whitfield-Gabrieli, S., Mick, E., Spencer, T., Faraone, S., Seidman, L., 2011. Relationship of DAT1 and adult ADHD to taskpositive and task-negative working memory networks. Psychiatry Res. 193, 7-16.

Brown, A.B., Biederman, J., Valera, E.M., Doyle, A.E., Bush, G., Spencer, T., Monuteaux, M.C., Mick, E., Whitfield-Gabrieli, S., Makris, N., LaViolette, P.S., Oscar-Berman, M., Faraone, S.V., Seidman, L.J., 2010. Effect of dopamine transporter gene (SLC6A3) variation on dorsal anterior cingulate function in attention-deficit/hyperactivity disorder. Am. J. Med. Genet. B Neuropsychiatr. Genet. 153B, 365-375.

Bédard, A.C., Schulz, K.P., Cook, E.H., Fan, J., Clerkin, S.M., Ivanov, I., Halperin, J.M., Newcorn, J.H., 2010. Dopamine transporter gene variation modulates activation of striatum in youth with ADHD. Neuroimage 53, 935-942.

Costa, A., Riedel, M., Müller, U., Möller, H.J., Ettinger, U., 2011. Relationship between SLC6A3 genotype and striatal dopamine transporter availability: a meta-analysis of human single photon emission computed tomography studies. Synapse 65, 998-1005.

Cubillo, A., Halari, R., Smith, A., Taylor, E., Rubia, K., 2011. A review of fronto-striatal and fronto-cortical brain abnormalities 
in children and adults with Attention Deficit Hyperactivity Disorder (ADHD) and new evidence for dysfunction in adults with ADHD during motivation and attention. Cortex.

Dougherty, D.D., Bonab, A.A., Spencer, T.J., Rauch, S.L., Madras, B.K., Fischman, A.J., 1999. Dopamine transporter density in patients with attention deficit hyperactivity disorder. Lancet 354, 2132-2133.

Dreher, J.C., Kohn, P., Kolachana, B., Weinberger, D.R., Berman, K.F., 2009. Variation in dopamine genes influences responsivity of the human reward system. Proc. Natl. Acad. Sci. USA 106, 617-622.

Dresel, S., Krause, J., Krause, K.H., LaFougere, C., Brinkbäumer, K., Kung, H.F., Hahn, K., Tatsch, K., 2000. Attention deficit hyperactivity disorder: binding of [99mTc]TRODAT-1 to the dopamine transporter before and after methylphenidate treatment. Eur. J. Nucl. Med. 27, 1518-1524.

Durston, S., Fossella, J.A., Mulder, M.J., Casey, B.J., Ziermans, T.B., Vessaz, M.N., Van Engeland, H., 2008. Dopamine transporter genotype conveys familial risk of attention-deficit/hyperactivity disorder through striatal activation. J. Am. Acad. Child Adolesc. Psychiatry 47, 61-67.

Faraone, S., Biederman, J., Mick, E., 2006. The age-dependent decline of attention deficit hyperactivity disorder: a metaanalysis of follow-up studies. Psychol. Med. 36, 159-165.

Forbes, E., Brown, S., Kimak, M., Ferrell, R., Manuck, S., Hariri, A., 2009. Genetic variation in components of dopamine neurotransmission impacts ventral striatal reactivity associated with impulsivity. Mol. Psychiatry, 14, 60-70.

Frances, A., 2000. Diagnostic and Statistical Manual of Mental Disorders, DSM-IV-TR. American Psychiatric Association, Washington DC.

Franke, B., Faraone, S.V., Asherson, P., Buitelaar, J., Bau, C.H., Ramos-Quiroga, J.A., Mick, E., Grevet, E.H., Johansson, S., Haavik, J., Lesch, K.P., Cormand, B. \& Reif, A. (2011) The genetics of attention deficit/hyperactivity disorder in adults, a review. Mol. Psychiatry.

Franke, B., Hoogman, M., Arias Vasquez, A., Heister, J.G., Savelkoul, P.J., Naber, M., Scheffer, H., Kiemeney, L.A., Kan, C.C., Kooij, J.J., Buitelaar, J.K., 2008. Association of the dopamine transporter (SLC6A3/DAT1) gene 9-6 haplotype with adult ADHD. Am. J. Med. Genet. B Neuropsychiatr. Genet. 147B, 1576-1579.

Franke, B., Vasquez, A.A., Johansson, S., Hoogman, M., Romanos, J., Boreatti-Huemmer, A., Heine, M., Jacob, C.P., Lesch, K.-P., Casas, M., Ribases, M., Bosch, R., Sanchez-Mora, C., GomezBarros, N., Fernandez-Castillo, N., Bayes, M., Halmoy, A., Halleland, H., Landaas, E.T., Fasmer, O.B., Knappskog, P.M., Heister, A.J.G.A.M., Kiemeney, L.A., Kooij, J.J.S., Boonstra, A.M., Kan, C.C., Asherson, P., Faraone, S.V., Buitelaar, J.K., Haavik, J., Cormand, B., Antoni Ramos-Quiroga, J., Reif, A., 2010. Multicenter analysis of the SLC6A3/DAT1 VNTR haplotype in persistent $A D H D$ suggests differential involvement of the gene in childhood and persistent ADHD. Neuropsychopharmacology 35, 656-664.

Gizer, I., Ficks, C., Waldman, I., 2009. Candidate gene studies of ADHD: a meta-analytic review. Hum. Genet. 126, 51-90.

Hahn, T., Heinzel, S., Dresler, T., Plichta, M.M., Renner, T.J., Markulin, F., Jakob, P.M., Lesch, K.P., Fallgatter, A.J., 2010. Association between reward-related activation in the ventral striatum and trait reward sensitivity is moderated by dopamine transporter genotype. Hum. Brain Mapp.

Heinz, A., Goldman, D., Jones, D., Palmour, R., Hommer, D., Gorey, J., Lee, K., Linnoila, M., Weinberger, D., 2000. Genotype influences in vivo dopamine transporter availability in human striatum. Neuropsychopharmacology 22, 133-139.

Hermans, E., Bos, P., Ossewaarde, L., Ramsey, N., Fernández, G., van Honk, J., 2010. Effects of exogenous testosterone on the ventral striatal BOLD response during reward anticipation in healthy women. Neuroimage 52, 277-283.
Hesse, S., Ballaschke, O., Barthel, H., Sabri, O., 2009. Dopamine transporter imaging in adult patients with attention-deficit/ hyperactivity disorder. Psychiatry Res. 171, 120-128.

Hoogman, M., Aarts, E., Zwiers, M., Slaats-Willemse, D., Naber, M., Onnink, M., Cools, R., Kan, C., Buitelaar, J., Franke, B., 2011. Nitric oxide synthase genotype modulation of impulsivity and ventral striatal activity in Attention Deficit/Hyperactivity Disorder and comparison subjects. Am. J. Psychiatry 168 (10), 1099-1106.

Jucaite, A., Fernell, E., Halldin, C., Forssberg, H., Farde, L., 2005. Reduced midbrain dopamine transporter binding in male adolescents with attention-deficit/hyperactivity disorder: association between striatal dopamine markers and motor hyperactivity. Biol. Psychiatry 57, 229-238.

Kebir, O., Joober, R., 2011. Neuropsychological endophenotypes in attention-deficit/hyperactivity disorder: a review of genetic association studies. Eur. Arch. Psychiatry Clin. Neurosci. 261, 583-594.

Knutson, B., Adams, C.M., Fong, G.W., Hommer, D., 2001. Anticipation of increasing monetary reward selectively recruits nucleus accumbens. J. Neurosci. 21, RC159.

Kooij, J., 2010. Adult ADHD. Diagnostic Assessment and Treatment. Pearson Assessment and Information BV, Amsterdam.

Kooij, J., Buitelaar, J., van den Oord, E., Furer, J., Rijnders, C., Hodiamont, P., 2005. Internal and external validity of attentiondeficit hyperactivity disorder in a population-based sample of adults. Psychol. Med. 35, 817-827.

Krause, J., 2008. SPECT and PET of the dopamine transporter in attention-deficit/hyperactivity disorder. Expert Rev. Neurother. 8, 611-625.

Krause, K.H., Dresel, S.H., Krause, J., Kung, H.F., Tatsch, K., 2000. Increased striatal dopamine transporter in adult patients with attention deficit hyperactivity disorder: effects of methylphenidate as measured by single photon emission computed tomography. Neurosci. Lett. 285, 107-110.

la Fougère, C., Krause, J., Krause, K.H., Josef Gildehaus, F., Hacker, M., Koch, W., Hahn, K., Tatsch, K., Dresel, S., 2006. Value of $99 \mathrm{mTC}$-TRODAT-1 SPECT to predict clinical response to methylphenidate treatment in adults with attention deficit hyperactivity disorder. Nucl. Med. Commun. 27, 733-737.

Larisch, R., Sitte, W., Antke, C., Nikolaus, S., Franz, M., Tress, W., Müller, H.W., 2006. Striatal dopamine transporter density in drug naive patients with attention-deficit/hyperactivity disorder. Nucl. Med. Commun. 27, 267-270.

Loo, S.K., Specter, E., Smolen, A., Hopfer, C., Teale, P.D., Reite, M.L., 2003. Functional effects of the DAT1 polymorphism on EEG measures in ADHD. J. Am. Acad. Child Adolesc. Psychiatry 42, 986-993.

Luman, M., Oosterlaan, J., Sergeant, J., 2005. The impact of reinforcement contingencies on $A D / H D$ : a review and theoretical appraisal. Clin. Psychol. Rev. 25, 183-213.

Mell, T., Wartenburger, I., Marschner, A., Villringer, A., Reischies, F., Heekeren, H., 2009. Altered function of ventral striatum during reward-based decision making in old age. Front. Hum. Neurosci. 3, 34.

Mier, D., Kirsch, P., Meyer-Lindenberg, A., 2010. Neural substrates of pleiotropic action of genetic variation in COMT: a metaanalysis. Mol. Psychiatry 15, 918-927.

Munafò, M., Brown, S., Hariri, A., 2008. Serotonin transporter (5HTTLPR) genotype and amygdala activation: a meta-analysis. Biol. Psychiatry 63, 852-857.

Nieratschker, V., Grosshans, M., Frank, J., Strohmaier, J., von der Goltz, C., El-Maarri, O., Witt, S.H., Cichon, S., Nöthen, M.M., Kiefer, F., Rietschel, M., 2012. Epigenetic alteration of the dopamine transporter gene in alcohol-dependent patients is associated with age. Addict. Biol..

Nikolova, Y.S., Ferrell, R.E., Manuck, S.B., Hariri, A.R., 2011. Multilocus genetic profile for dopamine signaling predicts ventral striatum reactivity. Neuropsychopharmacology 36, 1940-1947. 
Rommelse, N.N., Altink, M.E., Arias-Vásquez, A., Buschgens, C.J., Fliers, E., Faraone, S.V., Buitelaar, J.K., Sergeant, J.A., Franke, B., Oosterlaan, J., 2008. A review and analysis of the relationship between neuropsychological measures and DAT1 in ADHD. Am. J. Med. Genet. B Neuropsychiatr. Genet. 147B, 1536-1546.

Ruano, D., Abecasis, G.R., Glaser, B., Lips, E.S., Cornelisse, L.N., de Jong, A.P., Evans, D.M., Davey Smith, G., Timpson, N.J., Smit, A.B., Heutink, P., Verhage, M., Posthuma, D., 2010. Functional gene group analysis reveals a role of synaptic heterotrimeric $G$ proteins in cognitive ability. Am. J. Hum. Genet. 86, 113-125.

Schaid, D.J., Rowland, C.M., Tines, D.E., Jacobson, R.M., Poland, G.A., 2002. Score tests for association between traits and haplotypes when linkage phase is ambiguous. Am. J. Hum. Genet. 70, 425-434.

Scheres, A., Milham, M., Knutson, B., Castellanos, F., 2007. Ventral striatal hyporesponsiveness during reward anticipation in attention-deficit/hyperactivity disorder. Biol. Psychiatry 61, 720-724.

Shumay, E., Chen, J., Fowler, J.S., Volkow, N.D., 2011. Genotype and ancestry modulate brain's DAT availability in healthy humans. PLoS One 6, e22754.

Shumay, E., Fowler, J.S., Volkow, N.D., 2010. Genomic features of the human dopamine transporter gene and its potential epigenetic states: implications for phenotypic diversity. PLoS One 5, e11067.

Simon, V., Czobor, P., Bálint, S., Mészáros, A., Bitter, I., 2009. Prevalence and correlates of adult attention-deficit hyperactivity disorder: meta-analysis. Br. J. Psychiatry 194, 204-211.

Sonuga-Barke, E., 2003. The dual pathway model of AD/HD: an elaboration of neuro-developmental characteristics. Neurosci. Biobehav. Rev. 27, 593-604.

Sonuga-Barke, E., Bitsakou, P., Thompson, M., 2010. Beyond the dual pathway model: evidence for the dissociation of timing, inhibitory, and delay-related impairments in attention-deficit/ hyperactivity disorder. J. Am. Acad. Child Adolesc. Psychiatry 49, 345-355.

Spencer, T.J., Biederman, J., Madras, B.K., Faraone, S.V., Dougherty, D.D., Bonab, A.A., Fischman, A.J., 2005. In vivo neuroreceptor imaging in attention-deficit/hyperactivity disorder: a focus on the dopamine transporter. Biol. Psychiatry 57, 1293-1300.

Ströhle, A., Stoy, M., Wrase, J., Schwarzer, S., Schlagenhauf, F., Huss, M., Hein, J., Nedderhut, A., Neumann, B., Gregor, A.,
Juckel, A., Knutson, B., Lehmkuhl, U., Bauer, M., Heinz, A., 2008. Reward anticipation and outcomes in adult males with attentiondeficit/hyperactivity disorder. Neuroimage 39, 966-972.

Sánchez-Mora, C., Ribasés, M., Ramos-Quiroga, J., Casas, M., Bosch, R., Boreatti-Hümmer, A., Heine, M., Jacob, C., Lesch, K., Fasmer, O., Knappskog, P., Kooij, J., Kan, C., Buitelaar, J., Mick, E., Asherson, P., Faraone, S., Franke, B., Johansson, S., Haavik, J., Reif, A., Bayés, M., Cormand, B., 2010. Meta-analysis of brain-derived neurotrophic factor p.Val66Met in adult ADHD in four European populations. Am. J. Med. Genet. B Neuropsychiatr. Genet. 153B, 512-523.

van de Giessen, E., de Win, M.M., Tanck, M.W., van den Brink, W., Baas, F., Booij, J., 2009. Striatal dopamine transporter availability associated with polymorphisms in the dopamine transporter gene SLC6A3. J. Nucl. Med. 50, 45-52.

VanNess, S.H., Owens, M.J., Kilts, C.D., 2005. The variable number of tandem repeats element in DAT1 regulates in vitro dopamine transporter density. BMC Genet. 6, 55.

Volkow, N.D., Wang, G.J., Fowler, J.S., Gatley, S.J., Logan, J., Ding, Y.S., Hitzemann, R., Pappas, N., 1998. Dopamine transporter occupancies in the human brain induced by therapeutic doses of oral methylphenidate. Am. J. Psychiatry 155, 1325-1331.

Volkow, N.D., Wang, G.J., Newcorn, J., Fowler, J.S., Telang, F., Solanto, M.V., Logan, J., Wong, C., Ma, Y., Swanson, J.M., Schulz, K., Pradhan, K., 2007. Brain dopamine transporter levels in treatment and drug naïve adults with ADHD. Neuroimage 34 , 1182-1190.

Wilens, T.E., Biederman, J., Faraone, S.V., Martelon, M., Westerberg, D., Spencer, T.J., 2009. Presenting ADHD symptoms, subtypes, and comorbid disorders in clinically referred adults with ADHD. J. Clin. Psychiatry 70, 1557-1562.

Zhou, K., Chen, W., Buitelaar, J., Banaschewski, T., Oades, R.D., Franke, B., Sonuga-Barke, E., Ebstein, R., Eisenberg, J., Gill, M., Manor, I., Miranda, A., Mulas, F., Roeyers, H., Rothenberger, A., Sergeant, J., Steinhausen, H.C., Lasky-Su, J., Taylor, E., Brookes, K.J., Xu, X., Neale, B.M., Rijsdijk, F., Thompson, M., Asherson, P., Faraone, S.V., 2008. Genetic heterogeneity in ADHD: DAT1 gene only affects probands without CD. Am. J. Med. Genet. B Neuropsychiatr. Genet. 147B, 1481-1487. 